Folglich ist die Veränderlichkeit des Sterns, mit einer langen Periode (oder unregelmäßig) nicht ausgeschlossen. Eine Aufnahme, welche ich 1908.66 mit rotem Filter gemacht habe, gibt für die Größe des Sterns etwa 9 mo; also ist derselbe tief rot (Spektraltypus $M$ ?). Die angenäherte Position des Sterns ist:

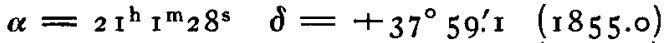

$$
\begin{aligned}
& 2 \text { I } 345+38 \text { I3.2 (1914.0). } \\
& \text { Pulkowo, I } 9 \text { I } 4 \text { Jan. } 28 . \quad S \text {. Kostinsky. }
\end{aligned}
$$

Zusatz. In Publ. Astron. Soc. Pacific 3. Ioo zeigt Herr Torvald Köhl das I 889 bemerkte Fehlen eines Sternes an, der auf einer Zeichnung der Ungebung von 6I Cygni von $R$. Falb vorkommt. Die genäherte Position dieses Sternes ist $21^{\mathrm{h}} \mathrm{O}^{\mathrm{m}} 55^{\mathrm{s}}+37^{\circ} 59^{\prime} \cdot 91855.0$. Herr $K \ddot{\partial h l}$ hat mir in dankens- werter Weise seine diesen Stern betreffende Korrespondenz mit Herrn Falb zur Verfügung gestellt. Aus derselben geht hervor, daß die den Stern enthaltende Zeichnung, die im Sirius August I870 publiziert ist, im Juni oder Juli I 870 angefertigt ist, und daß der Stern damals I I. Größe war. In der Zeichnung trägt der Stern die Nummer 15. Eine Identität mit dem Sterne, auf den die vorstehende Notiz von Herrn Kostinsky sich bezieht, erscheint ausgeschlossen. Dagegen hat der Stern Nr. I3 der Falbschen Skizze nach der Zeichnung die Koordinaten $1855.02 \mathrm{I}^{\mathrm{h}} \mathrm{I}^{\mathrm{m}} 27^{\mathrm{s}}+37^{\circ} 59^{\prime} \cdot 2$ und ist also offenbar mit dem Kostinskyschen Sterne identisch. Die visuelle Größe dieses Sternes wäre für I 870.5 gleichfalls zu I I $^{\mathbf{m}}$ anzusetzen.

$K$.

\title{
Bestätigung der Veränderlichkeit von zwei neu entdeckten Variablen.
}

8. 9 I 3 Persei (A.N. 194. I 5 I). Der Stern wurde 19 3 Sept. 6, 25 und 29 etwa $10^{\mathrm{m}} 5$ geschätzt; nachher ging der Abstieg rasch vor sich, und sein Licht scheint seit Nov. 4 bei der Größe ${ }^{1} 2^{\mathrm{m}} \cdot 5$ verweilt $z u$ haben. Angenommen, daß meine ersten Beobachtungen im September I9I3 nicht dem von dem Entdecker $D^{\prime}$ Esterre für I9I3 Jan. 3 I festgelegten Maximum entsprechen, muß die von $D^{\prime}$ Esterre angenommene Periode $\left(45^{\circ}\right)$ halbiert werden.

Dombaas, ig 4 Jan. 20.

\section{Genäherte Elemente:}

Max. $=241935^{\mathrm{I}}+228^{\mathrm{d}} \cdot E$. Amplit. $={ }_{10}^{\mathrm{m}} \cdot 6-\mathrm{I}^{\mathrm{m}} \cdot 5$. I 8. I9 3 Lyrae (A. N. 195.272). Der Stern war I9 I 3 Sept. 27 und Okt. 4 unsichtbar $\left(<12^{\mathrm{m}} \cdot 5\right)$, Nov. I 9 schwach sichtbar und Dez. I 8 etwa 10 mo. I 9 1 4 Jan. 17 war er wieder sehr schwach geworden.

Genäherte Elemente:

Max. $=2419677^{1}+227^{\mathrm{d}} \cdot E$. Amplit. $=10^{\mathrm{m}} \cdot 0-<12^{\mathrm{m}} \cdot 5$. S. Enebo.

\section{Ephemeride des Giacobinischen Kometen $1913 \mathrm{e.}$}

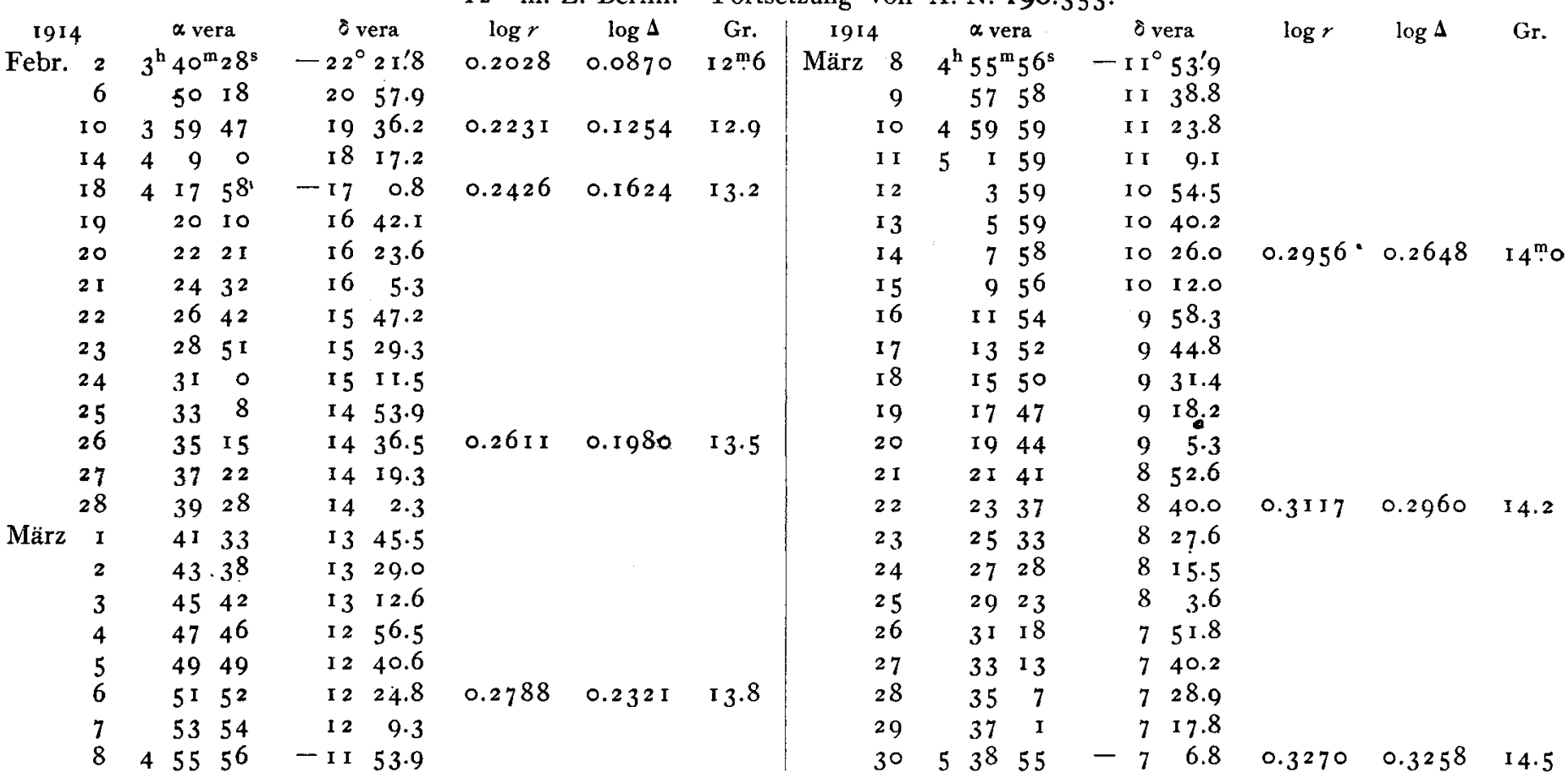

Nach einer Mitteilung von Direktor F. Gonnessiat vom 29. Januar I9I4 ist der Komet in Algier zuletzt Dez. I 5 und 17 beobachtet worden. Seitdem hat dort schlechtes Wetter und Mondschein Beobachtungen vereitelt. Am I5. Dez. war nach Herrn Renaux' Beobachtung die Korrektion dieser Ephemeride - I Is - o'.3. Spätere Beobachtungen sind nicht bekannt geworden.

Kiel, Bureau der Astronom. Nachr., I 9 I 4 Febr. I3 M. Ebell.

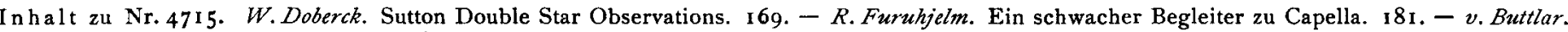
Bedeckung des II. Jupiterstrabanten durch I. I8I. - S. Kostinsky. Ein roter, vermutlich veränderlicher Stern 4.19I4 Cygni neben 61 Cygni. 181. - S. Enebo. Bestätigung der Veränderlichkeit von zwei neu entdeckten Variablen. 183. - $M$. Ebell. Ephemeride des Giacobinischen Kometen 1913 e. 183. 